\title{
Anaerobic Biodegradation of Oleic and Palmitic Acids: Evidence of Mass Transfer Limitations Caused by Long Chain Fatty Acid Accumulation onto the Anaerobic Sludge
}

\author{
M.A. Pereira, O.C. Pires, M. Mota, M.M. Alves \\ Centro de Engenharia Biológica, Universidade do Minho, 4710-057 Braga, Portugal; \\ telephone: +351.253604402; fax: +351.253678986; \\ e-mail: madalena.alves@deb.uminho.pt
}

Received 13 December 2004; accepted 24 March 2005

Published online 31 August 2005 in Wiley InterScience (www.interscience.wiley.com). DOI: 10.1002/bit.20548

\begin{abstract}
Palmitic acid was the main long chain fatty acids (LCFA) that accumulated onto the anaerobic sludge when oleic acid was fed to an EGSB reactor. The conversion between oleic and palmitic acid was linked to the biological activity. When palmitic acid was fed to an EGSB reactor it represented also the main LCFA that accumulated onto the sludge. The way of palmitic acid accumulation was different in the oleic and in the palmitic acid fed reactors. When oleic acid was fed, the biomass-associated LCFA ( $83 \%$ as palmitic acid) were mainly adsorbed and entrapped in the sludge that became "encapsulated" by an LCFA layer. However, when palmitic acid was fed, the biomass-associated LCFA (the totality as palmitic acid) was mainly precipitated in white spots like precipitates in between the sludge, which remained "non-encapsulated." The two sludges were compared in terms of the specific methanogenic activity (SMA) in the presence of acetate, propionate, butyrate, and $\mathrm{H}_{2} \mathrm{CO}_{2}$, before and after the mineralization of similar amounts of biomassassociated LCFA (4.6 and $5.2 \mathrm{~g}$ COD-LCFA/g of volatile suspended solids (VSS), for the oleic and palmitic acid fed sludge, respectively). The "non-encapsulated," sludge exhibited a considerable initial methanogenic activity on all the tested substrates, with the single exception of butyrate. However, with the "encapsulated" sludge only methane production from ethanol and $\mathrm{H}_{2} / \mathrm{CO}_{2}$ was detected, after a lag phase of about $50 \mathrm{~h}$. After mineralization of the biomass-associated LCFA, both sludges exhibited activities of similar order of magnitude in the presence of the same individual substrates and significantly higher than before. The results evidenced that LCFA accumulation onto the sludge can create a physical barrier and hinder the transfer of substrates and products, inducing a delay on the initial methane production. Whatever the mechanism, metabolic or physical, that is behind this inhibition, it is reversible, being eliminated after the depletion of the biomass-associated LCFA. (c) 2005 Wiley Periodicals, Inc.
\end{abstract}

Keywords: LCFA; methanogenic activity; transport limitations

Correspondence to: M.M. Alves

Contract grant sponsors: Fundação para a Ciência e Tecnologia (FCT); Fundo Social Europeu (FSE)

\section{INTRODUCTION}

When an oleic acid (C18:1) based effluent is continuously fed to an anaerobic reactor, a significant accumulation of long chain fatty acids (LCFA) occurs, associated to the sludge, palmitic acid (C16:0) representing more than $80 \%$ of the most expected $\beta$-oxidation intermediates (C10:0-C18:0) (Pereira et al., 2002). The accumulation of palmitic acid was also reported by other authors. Salminen et al. (2001) reported that during the batch degradation of solid poultry slaughterhouse wastes, stearate was consumed faster than it was produced and also that palmitic acid was the most abundant LCFA detected in the medium. Beccari et al. (1998) applied a two-reactor system with partial phase separation for treating olive oil effluents and reported that in the conversion between oleic acid and palmitic acid, the saturation from oleic to stearic was the limiting step, whereas the first step of $\beta$-oxidation (stearic to palmitic) proceeded quickly. Also, Lalman and Bagley $(2000,2001)$ reported that palmitic acid was the primary detected product from oleic and linoleic acids, and that stearic acid was not detected.

Adsorption, precipitation with divalent ions, and entrapment in the flocculent structure of the sludge are the mechanisms responsible for the LCFA accumulation. Adsorption is widely reported in the literature and, besides problems of sludge flotation, this phenomenon was considered to be the main factor of LCFA toxicity due to physical interactions with the cell wall, affecting its transport and protective functions (Galbraith and Miller, 1973). A permanent toxic effect and a bactericidal toxic effect of LCFA were reported and accepted for years (Angelidaki and Ahring, 1992; Rinzema et al., 1994). However, studies conducted in our research group clearly demonstrated that LCFA toxicity is not permanent and that LCFA do not exert a bactericidal effect towards methanogens. It was found that LCFA, provided they are associated to the biomass, could be efficiently mineralized and that after the mineralization, the specific methanogenic activity (SMA) was significantly enhanced. 
This finding was observed for sludge with specific LCFA contents in the range from 1 to $5 \mathrm{~g} \mathrm{COD} / \mathrm{g}$ of volatile suspended solids (VSS) (Pereira et al., 2004). A reasonable hypothesis to explain this behavior is that LCFA exert a reversible inhibitory effect. However, transport limitation effects imposed by the LCFA accumulation onto the anaerobic sludge may also occur. The aim of this work was to add insights on two key aspects of anaerobic biodegradation of LCFA:

I) The role of the biological activity on the conversion between oleic and palmitic acids when oleic acid is the sole organic carbon source fed.

II) The role of mass transport limitations imposed by the accumulation of palmitic acid.

Two sets of experiments were designed. In experiment I, oleic acid was fed to two reactors previously inoculated with active and inactivated sludge. Biomass-associated LFCA were extracted and analyzed.

The experiment II was planed to obtain sludge loaded with LCFA (essentially palmitic acid) in different ways of association with the cells. It had been previously observed that, when feeding palmitic acid, this LCFA accumulated in between the sludge flocs, mainly as individualized precipitate-like forms. When feeding oleic acid, a conversion between oleic and palmitic acid occurred and palmitic acid accumulated mainly adsorbed onto the sludge or entrapped in the bacterial flocculent aggregates. The three main mechanisms of LCFA accumulation are schematically presented in Figure 1.

\section{MATERIALS AND METHODS}

\section{Experiment I: Role of Biological Activity on the Accumulation of LCFA onto the Anaerobic Sludge}

Two 10 L EGSB reactors, Ract and Rinact, were operated during 51 and 38 days, respectively with a constant sodium oleate concentration of $6 \mathrm{~g}$ COD/L and HRT of 1 day. No cosubstrate was added. Ract was inoculated with $1 \mathrm{~L}$ of suspended sludge ( $43.7 \mathrm{~g} \mathrm{VSS} / \mathrm{L}$ ) previously acclimated to oleic acid. This sludge, collected at the end of a lab scale reactor operation, was kept under anaerobic conditions, at $4^{\circ} \mathrm{C}$, until the beginning of the actual experiment, during a total period of 5 months. The appearance of the sludge was gelatinous, seeming to be "encapsulated" by a whitish matter and prior
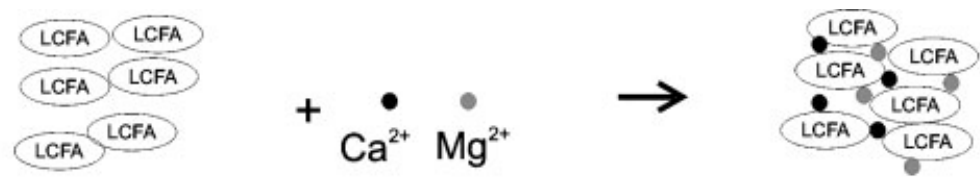

( a )

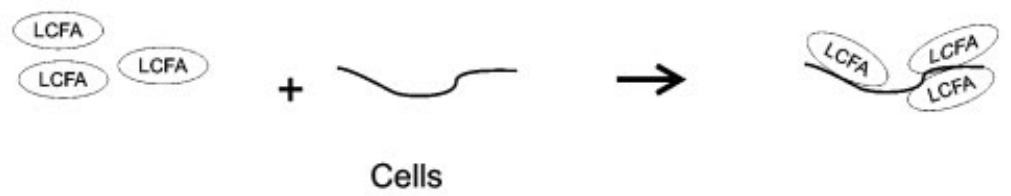

(b)

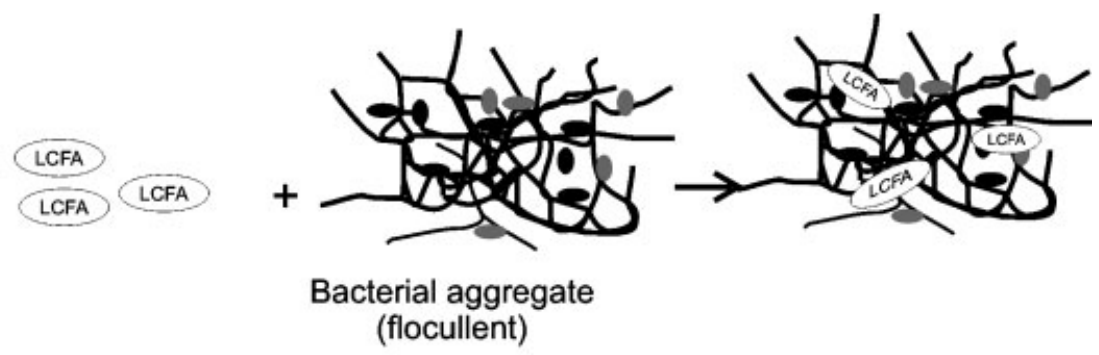

(c)

Figure 1. Mechanisms of biomass-associated LCFA accumulation. a: Precipitation. b: Adsorption. c: Entrapment. Schematic representation. 
to inoculation it was let to degrade the biomass-associated substrate in batch mode at $150 \mathrm{rpm}$ and $37^{\circ} \mathrm{C}$, until no more biogas was produced. Rinact was inoculated with $1 \mathrm{~L}$ of the same sludge (43.7 $\mathrm{g}$ VSS/L) inactivated by autoclaving, as described by Hwu (1997). Routine reactor performance was monitored by determining influent and effluent $\mathrm{COD}, \mathrm{pH}$, and percent of $\mathrm{CH}_{4}$ in the biogas.

Biomass samples were collected from the reactors on days 28, 30, and 37 and the LCFA content (biomass-associated) was determined.

\section{Experiment II: Role of Mass Transport Limitations Imposed by the Accumulation of Palmitic Acid in Different Ways of Interaction With the Cells}

Two 1 L EGSB reactors were fed with oleic (R1) and palmitic (R2) acids, respectively. The influent LCFA concentration was $4 \mathrm{~g} \mathrm{COD/L}$, the HRT was set at 1 day and the temperature was $37^{\circ} \mathrm{C}$. Floating sludge was recycled to the influent port at a rate of $4 \mathrm{~L} /$ day.

During the start-up period, which lasted 28 days, the substrate consisted of skim milk (50\% COD) and the corresponding individual LCFA (50\% COD) diluted with tap water. Macro and micronutrients were added according to the composition described elsewhere (Alves et al., 2001). Macronutrients solution $(0.6 \mathrm{~mL})$ was added per gram of COD fed and $1 \mathrm{~mL}$ of micronutrients per liter of influent feed. To give suitable alkalinity $5 \mathrm{~g} \mathrm{NaHCO}_{3} / \mathrm{L}$ were added. From the day 28 on, the carbon source was exclusively composed by sodium oleate in R1 and palmitic acid in R2. During this time, a nitrogen supplement was added to the macronutrients solution in order to maintain a ratio COD/N/P of 200:5:1.1.

Due to the low solubility of palmitic acid in aqueous media $\left(7.2 \mathrm{mg} / \mathrm{L}\right.$ in water at $\left.20^{\circ} \mathrm{C}\right)$, to overcome solid sedimentation in the feed tank and to promote a homogeneous emulsion this feedstock was homogenized in a Euroturrax T20 (IKA Labortechnik, Germany). The influent COD was monitored to confirm that the desired value was assured. The $\mathrm{pH}$ was kept near the neutrality.

\section{Seed Sludge}

The seed sludge was obtained from a local municipal sludge digester (Braga WWTP, Portugal) and was let to acclimate to oleate in the presence of skim milk as co-substrate $(50 \%$ COD) during a period of 100 days in a fed-batch laboratorial reactor. After the acclimation process, $500 \mathrm{~mL}$ of this sludge (7.75 g VSS/L) were inoculated in each EGSB reactor.

Prior to inoculation the acclimated suspended sludge was characterized in terms of SMA, oleic, and palmitic acid toxicity towards the aceticlastic methanogens, as well as in terms of biodegradation capacity of the two individual LCFA. Tables I and II summarize the obtained results.

As shown in Table I the sludge exhibited no detectable activity against propionate and moderately low SMA values in the presence of the other substrates. In terms of toxicity limit to the LCFA under study, a higher $\mathrm{IC}_{50}$ value was found
Table I. Specific methanogenic activities and oleic or palmitic acid toxicity towards acetoclastic methanogens, exhibited by the inoculum $($ mean $\pm \mathrm{SD})$.

Specific methanogenic activity

in the presence

(mg COD- $\mathrm{CH}_{4} / \mathrm{g}$ VSS/day)

\begin{tabular}{lc}
\hline Acetate & $146 \pm 15$ \\
Propionate & n.d. \\
Butyrate & $80 \pm 18$ \\
Ethanol & $72 \pm 4$ \\
$\mathrm{H}_{2} / \mathrm{CO}_{2}$ & $581 \pm 33$ \\
Oleic acid toxicity limit $\left(\mathrm{IC}_{50}\right)$ & $70 \pm 10 \mathrm{mg} / \mathrm{L}$ \\
Palmitic acid toxicity limit $\left(\mathrm{IC}_{50}\right)$ & $1100 \pm 50 \mathrm{mg} / \mathrm{L}$
\end{tabular}

n.d., non-detectable.

for palmitic than for oleic acid, revealing a higher tolerance of the aceticlastic methanogens to this LCFA. Concerning LCFA biodegradation capacity (Table II), and for the range of concentrations studied, the sludge exhibited slightly higher methane production rates from oleic than from palmitic acid, but during oleic acid biodegradation, significantly higher lag phases preceding the maximum methane production were detected.

\section{Routine Analysis}

Chemical oxygen demand (COD) and VSS were determined according to Standard Methods (APHA et al., 1989). Volatile fatty acids (VFA) were determined by high-performance liquid chromatography (HPLC) using a Chrompack column $(300 \times 6.5 \mathrm{~mm})$ and a mobile phase of $5 \mathrm{mM}$ sulphuric acid $\left(\mathrm{H}_{2} \mathrm{SO}_{4}\right)$ at $0.7 \mathrm{~mL} / \mathrm{min}$. The column was set at $40^{\circ} \mathrm{C}$ and the detection was spectrophotometric at $220 \mathrm{~nm}$.

Methane content of the biogas was measured by gas chromatography (GC) using a Chrompack Haysep Q (80$100 \mathrm{mesh}$ ) column, with $\mathrm{N}_{2}$ carrier gas at $30 \mathrm{~mL} / \mathrm{min}$ and a flame-ionization detector (FID). Temperatures of the injection port, column, and FID were $120^{\circ} \mathrm{C}, 40^{\circ} \mathrm{C}$, and $130^{\circ} \mathrm{C}$, respectively.

Table II. Oleic and palmitic acid biodegradation capacity exhibited by the inoculum (mean $\pm \mathrm{SD}$ )

\begin{tabular}{lcc}
\hline & & Lag-phase \\
Maximum biodegradation rate (mg COD-CH$/$ /g VSS/day) & & \\
\hline Oleic acid concentrations (mg/L) & & n.d. \\
100 & $17 \pm 7$ & n.d. \\
300 & $25 \pm 1$ & $70 \pm 5$ \\
500 & $56 \pm 5$ & $90 \pm 2$ \\
700 & $62 \pm 2$ & $110 \pm 10$ \\
900 & $62 \pm 8$ & n.d. \\
Palmitic acid concentrations (mg/L) & & n.d. \\
100 & $3 \pm 2$ & n.d. \\
300 & $15 \pm 8$ & $50 \pm 2$ \\
500 & $12 \pm 7$ & $60 \pm 3$ \\
700 & $23 \pm 4$ & $40 \pm 4$ \\
900 & & \\
\hline
\end{tabular}

n.d., non-detectable. 


\section{Microscopic Observations}

Scanning electron microphotographs were obtained in a Leica S360 microscope. Samples were fixed with 3\% (wt/vol) gluteraldehyde solution in cacodyilate buffer, $\mathrm{pH} 7.2$, and dehydrated with ascending concentration ethanol solutions $(10 \%, 25 \%, 50 \%, 75 \%, 90 \%$, and $100 \%)$. Prior to microscopic examination, samples were sputter-coated with gold.

\section{Extraction and GC Analysis of LCFA Accumulated onto the Sludge}

After two consecutive washings and centrifugations $(4,000 \mathrm{rpm}, 10 \mathrm{~min})$ with anaerobic basal medium, an aliquot of sludge sample was dried at $105^{\circ} \mathrm{C}$, weighed and placed into separating funnels. A solution of internal standard (pentadecanoic acid-C15) was added to the sample, and, after acidification to $\mathrm{pH} 2$, a multiple extraction with $5 \times 1 \mathrm{~mL}$ of petroleum ether was applied. The ether phase was transferred to glass vials, immediately capped, and stored at $-20^{\circ} \mathrm{C}$. LCFA (C10-C18) concentration was determined by a gas chromatograph (CP-9001 Chrompack) equipped with an FID and a split/splitless injector. LCFA were separated on an FFAP-CB $25 \mathrm{~m} \times 0.32 \mathrm{~mm} \times 0.3 \mu \mathrm{m}$ column (Chrompack), using nitrogen $\left(\mathrm{N}_{2}\right)$ as carrier gas at $35 \mathrm{KPa}, 31: 1$ split rate. Oven temperature was $40^{\circ} \mathrm{C}$ for $2 \mathrm{~min}$, with a $5^{\circ} \mathrm{C} / \mathrm{min}$ ramp to $250^{\circ} \mathrm{C}$, and a final hold at $250^{\circ} \mathrm{C}$ for $15 \mathrm{~min}$.

\section{Batch Experiments}

\section{Specific Methanogenic Activity (SMA) Tests}

These tests were performed using a pressure transducer technique (Coates et al., 1996; Colleran et al., 1992). The pressure increase developed in the batch vials $(25 \mathrm{~mL})$ fed with non-gaseous substrates $(30 \mathrm{mM}$ acetate, $30 \mathrm{mM}$ propionate, $15 \mathrm{mM}$ butyrate, and $30 \mathrm{mM}$ ethanol) or pressure decrease in vials $(75 \mathrm{~mL})$ previously pressurized (1 bar) with gaseous substrates $\left(\mathrm{H}_{2} / \mathrm{CO}_{2}-80: 20 \mathrm{vol} / \mathrm{vol}\right)$ was monitored, using a hand held pressure transducer capable of measuring a pressure variation of 2 bar ( 0 to $\pm 202.6 \mathrm{kPa}$ ) over a device range of -200 to $+200 \mathrm{mV}$, with a minimum detectable variation of $0.005 \mathrm{bar}$, corresponding to $0.05 \mathrm{~mL}$ biogas in $10 \mathrm{~mL}$ headspace. The basal medium used in all the batch experiments was made up with demineralized water, was composed of cysteine-HCL $(0.5 \mathrm{~g} / \mathrm{L})$ and sodium bicarbonate $(3 \mathrm{~g} / \mathrm{L})$, the $\mathrm{pH}$ was adjusted to $7.0-7.2$ with $\mathrm{NaOH} 8 \mathrm{~N}$ and was prepared under strict anaerobic conditions. The VSS concentration in each vial was in the range of $2-5 \mathrm{~g} / \mathrm{L}$. Methane content of the biogas was measured by GC as described above. The values of methane production were corrected for the standard temperature and pressure conditions (STP). Blank controls were used for liquid substrates (no added substrate) and for gaseous substrates (pressurized with $\mathrm{N}_{2} / \mathrm{CO}_{2}-80: 20 \mathrm{vol} / \mathrm{vol}$ at 1 bar). All the batch experiments were performed in triplicate assays. SMA values were determined by dividing the initial slope of the methane production curve by the VSS content of each vial at the end of the experiment and were expressed in $\mathrm{mL} \mathrm{CH}_{4} / \mathrm{g} \mathrm{VSS/day,}$ which were then converted to the equivalent COD. Background methane production due to the residual substrate was discounted.

Ideally the VSS values used to express the SMA should be the VSS initially present in the vials. However, those values account for all organic matter, including cells and biomassassociated LCFA, which significantly affect the values in the present case. To obtain the VSS content that accounts only for the cells, the methane production in the test vials was followed until stabilization in order to guarantee that all LCFA associated to the biomass was mineralized. This procedure may be questionable as some biomass growth can occur, underestimating the initial SMA. However, the error associated to this factor is certainly lower due to the slow growth rate of anaerobic biomass when compared to the huge amount of LCFA present in the sludge.

It should be referred that, concerning the SMA in the presence of indirect methanogenic substrates, the methane production rate will only be a valid measurement of the syntrophic activity on those substrates, when the aceticlastic and hydrogenophilic activities are not rate limiting (Dolfing and Bloemen, 1985).

\section{Assessment of SMA Before and After Allowing the Mineralization of the Biomass-Associated LCFA}

The SMA of the sludge before and after degrading the biomass-associated LCFA accumulated during the continuous load was compared using parallel assays. In the first set of vials the SMA against acetate, propionate, butyrate, ethanol and $\mathrm{H}_{2} / \mathrm{CO}_{2}$ were determined in duplicate, using the same pressure transducer technique described before. In the other set of vials, no substrate was added but the degradation of the biomass-associated LCFA was followed until stabilization. After this stabilization, the vials were depressurized, vented with $\mathrm{N}_{2} / \mathrm{CO}_{2}(80: 20 \mathrm{vol} / \mathrm{vol})$ and the SMA with the same substrates was measured as described for the first set of vials.

The cumulative methane production at the end of the blank control assays, without any added organic carbon source, calcium or nutrients, was considered an indirect measurement of the amount of biomass-associated LCFA, as previously described (Pereira et al., 2004). The specific LCFA content was then determined by dividing the maximum plateau achieved in the methane production curve by the VSS content of each vial at the end of the experiment and was expressed as $\mathrm{mg} \mathrm{COD/g} \mathrm{VSS}$.

\section{Toxicity and LCFA Mineralization Assays}

Toxicity tests were performed using the same pressure transducer technique previously described for the methanogenic activity measurements. Oleic and palmitic acids 
were the potential individual toxicants at concentrations in the range of $100-900 \mathrm{mg} / \mathrm{L}$. Due to the lower toxicity of palmitic acid towards the trophic group under study, concentrations up to $2,500 \mathrm{mg} / \mathrm{L}$ were tested. Acetate $(30 \mathrm{mM})$ was added, in order to select for he acetoclastic trophic group. The choice of this trophic group for the toxicity studies was based on its generalized higher susceptibility to adverse conditions (Yang and Speece, 1986) and specifically to the presence of oleic acid (Hanaki et al., 1981), along with its important metabolic role on the anaerobic digestion process (Gujer and Zehnder, 1983). The individual LCFA concentration that caused a 50\% relative methanogenic aceticlastic activity loss was defined as the toxicity index $\left(\mathrm{IC}_{50}\right)$.

In the LCFA mineralization assays, oleic or palmitic acids were the sole substrate added to the vials at concentrations in the range $100-900 \mathrm{mg} / \mathrm{L}$.

\section{RESULTS AND DISCUSSION}

\section{Experiment I: Role of Biological Activity on the Accumulation of LCFA onto the Anaerobic Sludge}

In a previous work, palmitic acid was found to be the most important LCFA that accumulated onto anaerobic sludge when oleic acid was fed as the sole organic carbon source (Pereira et al., 2002). In order to demonstrate that the conversion between oleic and palmitic acids directly depends on the presence of biological activity, a continuous experiment was run with two EGSB reactors fed with oleic acid at $6 \mathrm{~kg} \mathrm{COD} / \mathrm{m}^{3} /$ day. In one of the reactors (Ract) active sludge previously acclimated to oleic acid was inoculated and in the other reactor (Rinact) the same sludge was inoculated, but after an inactivation process.

Figure 2 represents the time course of the soluble COD removal efficiency of Ract and Rinact, as well as the $\mathrm{pH}$ in the feed and in the effluent of both reactors. Although removal efficiency and percent of methane were very low during the trial period, a clear difference between Ract and Rinact was observed, both in terms of removal efficiency (average value of 35\% in Ract and 14\% in Rinact) as well as in terms of methane content (20\% and $0 \%$ in Ract and Rinact, respectively). Also the different $\mathrm{pH}$ values recorded, clearly indicate that some biological activity was detected in Ract, but not in Rinact. The low performance of the active reactor should be result of the high load of oleic acid applied since the beginning $\left(6 \mathrm{~kg} \mathrm{COD} / \mathrm{m}^{3} /\right.$ day $)$, without any start-up strategy.

On day 28, sludge samples from Ract and Rinact were taken for extraction and GC analysis. The LCFA content of the feed was also analyzed in the same way and confirmed within an error of $10 \%$ the obtained value from the COD analysis. In the active reactor (Ract) the main LCFA detected was palmitic acid, at a concentration 2.8 times higher than the exhibited by oleic acid. In Rinact, inoculated with inactivated sludge, however, oleic acid was the main LCFA accumulated, at a concentration eight times higher than palmitc acid. The same analysis repeated on days 30 and 37, revealed the same pattern, being palmitic acid concentration 3.6 and 52 times
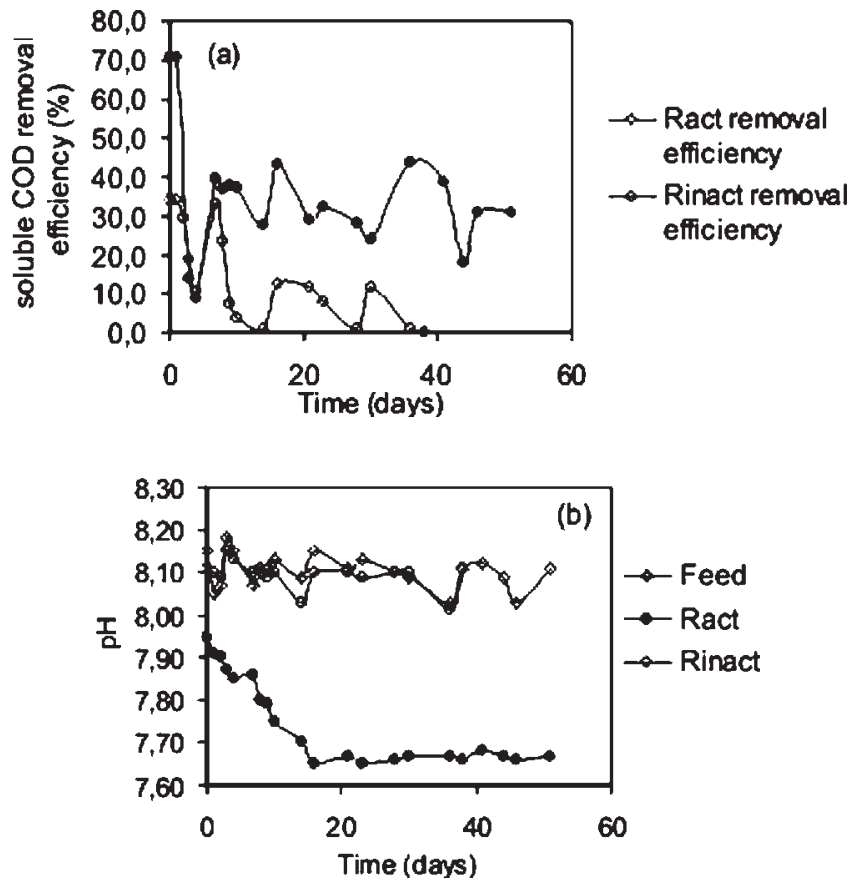

Figure 2. Time course of (a) soluble COD removal efficiency in the active (RI) and in the inactivated (RII) reactors. (b) $\mathrm{pH}$ in the feed and in the effluent of each reactor.

higher than oleic acid concentration, in the active sludge, respectively. This increasing accumulation of palmitic acid along the operation can be due to an inhibition of palmitate degradation by the continuously fed oleic acid, as previously reported (Pereira et al., 2002). From the present results it is evident that the transformation of oleic acid to palmitic acid is dependent on the biological activity, is a fast and nonlimiting step in oleic acid degradation. The accumulation of palmitic acid onto the sludge suggests that its further degradation is a difficult step under continuous operation. Hanaki et al. (1981) also studied the accumulation of lipids and LCFA onto anaerobic sludge and concluded that a fast adsorption of LCFA occurred. According to this author, LCFA accumulation was attributed to their inhibitory effect to its own $\beta$-oxidation. However, these experiments were in batch assays during whole milk degradation and no relevant information or discussion was addressed to the identification of individual LCFA.

\section{Experiment II: The Role of Mass Transport Limitations Imposed by the Accumulation of Palmitic Acid in Different Ways of Interaction With the Cells}

\section{Reactor Operation and Performance}

After a start-up of 28 days with skim milk as co-substrate (50\% COD) and progressive decrease of the HRT, the seed sludge was continuously loaded with oleate (R1) or palmitate 
Table III. Operating conditions and performance of R1 and R2 (mean \pm SD).

\begin{tabular}{|c|c|c|c|c|c|c|c|}
\hline $\begin{array}{l}\text { Time } \\
\text { (days) }\end{array}$ & $\begin{array}{l}\text { HRT } \\
( \pm 0.01) \\
\text { (days) }\end{array}$ & $\begin{array}{l}\text { Influent } \\
\text { COD } \\
(\mathrm{g} / \mathrm{L})\end{array}$ & $\begin{array}{c}\text { COD } \\
\text { Removal efficiency } \\
(\%)\end{array}$ & $\begin{array}{l}\text { Effluent } \\
\text { VFA-COD } \\
(\mathrm{g} / \mathrm{L})\end{array}$ & $\begin{array}{l}\text { Effluent } \\
\text { VSS } \\
(\mathrm{g} / \mathrm{L})\end{array}$ & $\begin{array}{l}\mathrm{CH}_{4} \\
(\%)\end{array}$ & $\begin{array}{l}\text { Biogas } \\
\text { (L/L/day) }\end{array}$ \\
\hline \multicolumn{8}{|l|}{ R1 } \\
\hline $0-28$ & $2.7-1.18$ & $3.9( \pm 0.3)$ & $65.4-93.1$ & $\mathrm{~b}$ & $\mathrm{~b}$ & $48.4-69.4$ & $\left({ }^{b}\right)-0.28$ \\
\hline $28-75$ & 1.18 & $3.9( \pm 0.3)$ & $80.3^{\mathrm{a}}( \pm 5.4)$ & $0.32^{\mathrm{a}}( \pm 0.09)$ & $0.88^{\mathrm{a}}( \pm 0.24)$ & $54.9^{\mathrm{a}}( \pm 8.3)$ & $0.16^{\mathrm{a}}( \pm 0.05)$ \\
\hline \multicolumn{8}{|l|}{$\mathrm{R} 2$} \\
\hline $0-28$ & $2.7-1.14$ & $3.7( \pm 0.3)$ & $61.6-90.1$ & b & b & $47.2-62.4$ & $\left({ }^{b}\right)-0.25$ \\
\hline $28-75$ & 1.14 & $3.7( \pm 0.3)$ & $92.8^{\mathrm{a}}( \pm 2.5)$ & $0.08^{\mathrm{a}}( \pm 0.03)$ & $0.76^{\mathrm{a}}( \pm 0.46)$ & $51.1^{\mathrm{a}}( \pm 6.4)$ & $0.13^{\mathrm{a}}( \pm 0.07)$ \\
\hline
\end{tabular}

(R2) at a constant concentration of $4 \mathrm{~g}$ COD/L. Table III summarizes the average operation conditions and performance for R1 and R2.

During the continuous operation, R2 exhibited a better performance in terms of removal efficiency, VFA and VSS effluent levels. However, in R1 a methane production $25 \%$ higher than that achieved in R2 was obtained. Nevertheless, in both reactors a considerable low mineralization of the fed LCFA was achieved, with methane yields as low as 33 and $29 \mathrm{~L} \mathrm{CH}_{4} / \mathrm{kg} \mathrm{COD}$ removed, in $\mathrm{R} 1$ and $\mathrm{R} 2$, respectively, revealing a considerable accumulation of non-mineralized substrate. Acetate was the only VFA detected in the effluent of both reactors, representing $39 \%$ and $29 \%$ of the total soluble effluent COD, in R1 and R2, respectively.

It is known that, besides adsorption onto the sludge or entrapment, precipitation with divalent ions can be responsible for LCFA removal (Hanaki et al., 1981; Roy et al., 1985) and thus justify COD accumulation in a bioreactor. Assuming that calcium and magnesium can exhibit similar effects, the molar ratio of oleate or palmitate to divalent ions $\left(\mathrm{Ca}^{2+}+\right.$ $\mathrm{Mg}^{2+}$ ) present during the trial period was determined (Table IV). These values were calculated considering the magnesium supplied in the macronutrients and the contribution of the calcium content present in the tap water. Based on the stoichiometric ratio 2 (each divalent ion can theoretically precipitate two LCFA molecules), the maximum LCFACOD that could be precipitated during operation was determined and compared to the total COD accumulated in the reactors (Table III). This comparison has shown that, even if all the existing divalent ions had precipitated the fed LCFA, this phenomenon couldn't account for all COD accumulated in the reactors, evidencing that adsorption and/or entrapment phenomena had an important contribution on LCFA removal.
As expected from previous observations, at the end of the continuous operation (day 75), the sludge fed with oleic acid (sludge 1), exhibited the typical whitish greasy aspect referred in the literature as related to LCFA adsorption (Hwu, 1997). However, the sludge fed with palmitic acid (sludge 2), kept its original dark aspect where whitish spots were eye perceptible, suggesting the accumulation of LCFA mainly as individualized precipitate-like forms rather than adsorbing onto the sludge. Therefore, sludge 1 appeared to be "encapsulated" by the accumulated LCFA presenting a higher degree of intimate association with the accumulated LCFA than sludge 2.

Microscopic inspection of both sludges supported this consideration (Fig. 3). Indeed, the presence of a non-biologic matrix entrapping the microorganism could be visualized in sludge 1 (Fig. 3a) and seemed to be absent in sludge 2 (Fig. 3b). In this latest, the presence of several crystal-like forms of variable size could be observed amid the biomass (Fig. 3c).

The extraction and GC analysis of the accumulated matter present in both sludge revealed that palmitic acid was the main LCFA present, representing $83 \%$ of the total LCFA present in the sludge 1 and the totality of the LCFA present in the sludge 2 (Table V).

\section{Effect of the Accumulated LCFA on the Methanogenic Activity Measurements}

The sludge collected from RI and from RII at the end of the operation, contained palmitic acid as the main LCFA accumulated. When incubated in batch assays both sludges were able to produce methane exclusively from the biomassassociated LCFA (Fig. 4). As described before, the maximum

Table IV. Molar ratio of each LCFA to calcium and magnesium ions during the trial period (days 28-75).

\begin{tabular}{lccc}
\hline & $\begin{array}{c}\text { Molar ratio LCFA/ } \\
\left(\mathrm{Ca}^{2+}+\mathrm{Mg}^{2+}\right)\end{array}$ & $\begin{array}{c}\text { LCFA-COD removed by } \\
\text { precipitation }(\mathrm{g} / \mathrm{L} / \mathrm{day})^{\mathrm{a}}\end{array}$ & $\begin{array}{c}\text { Total COD accumulated } \\
(\mathrm{g} / \mathrm{L} / \text { day })\end{array}$ \\
\hline R1-oleate & 4.10 & 1.93 & 2.40 \\
R2-palmitate & 4.47 & 1.76 & 2.82 \\
\hline
\end{tabular}

${ }^{\mathrm{a}}$ Theoretical values. 

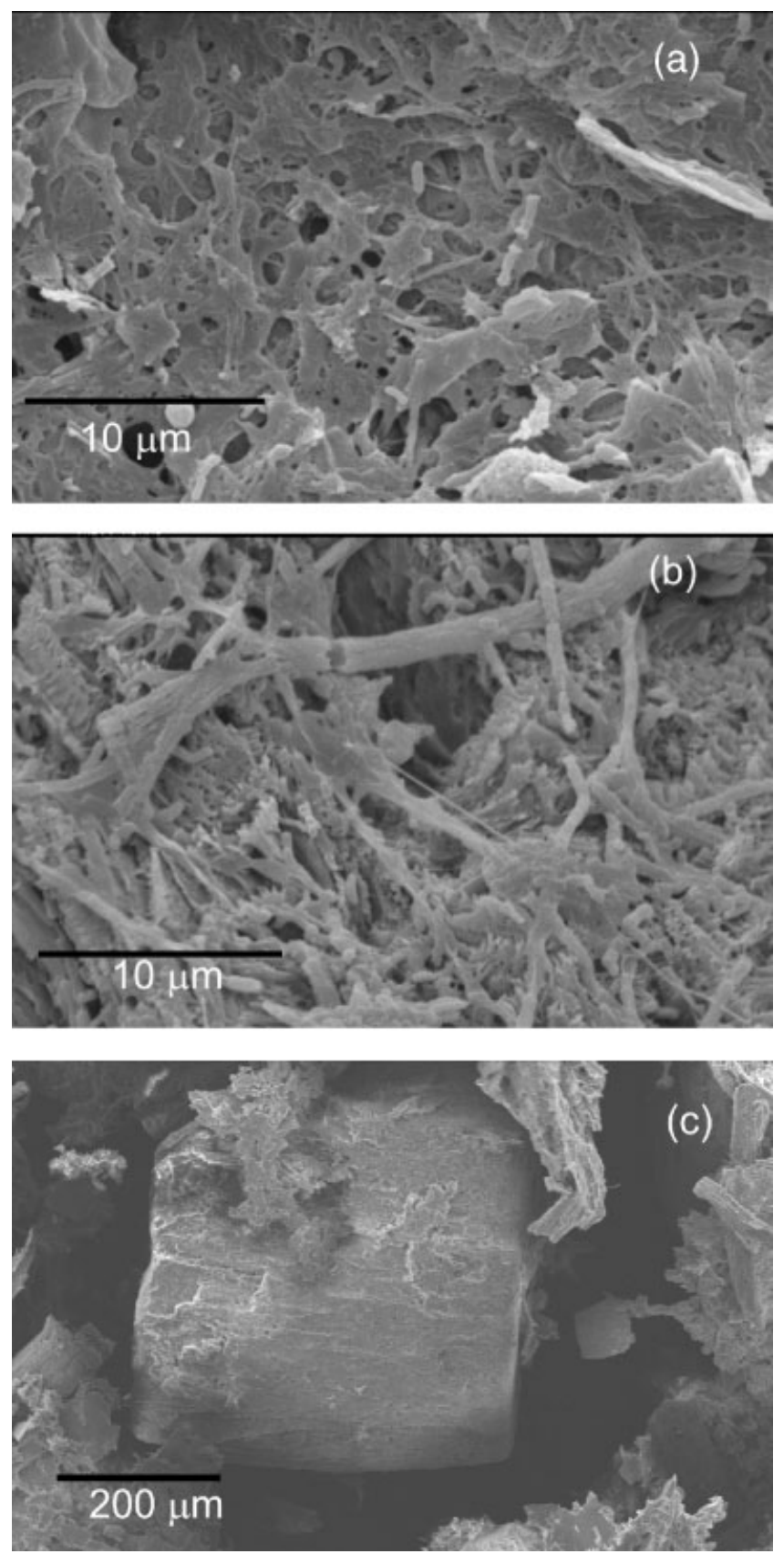

Figure 3. Scanning electron microphotographs of: sludge 1 (a) and sludge 2 (b and $\mathbf{c})$.

Table V. LCFA content of the accumulated matter present in sludge 1 and sludge 2 , at the end of the continuous run (mean $\pm \mathrm{SD}$ ).

\begin{tabular}{lcc}
\hline \multirow{2}{*}{ LCFA } & \multicolumn{2}{c}{$(\mathrm{mg} / \mathrm{mg}$ dry weight $)$} \\
\cline { 2 - 3 } & Sludge 1 & Sludge 2 \\
\hline Lauric acid (C12:0) & n.d. & n.d. \\
Myristic acid (C14:0) & $0.015 \pm 0.00$ & n.d. \\
Palmitic acid (C16:0) & $0.265 \pm 0.01$ & $0.286 \pm 0.21^{\mathrm{a}}$ \\
Stearic acid (C18:0) & $0.019 \pm 0.00$ & n.d. \\
Oleic acid (C18:1) & $0.019 \pm 0.00$ & n.d. \\
\hline
\end{tabular}

n.d., non-detectable.

${ }^{a}$ The high SD value is due to the highly heterogeneous distribution of the LCFA among the sludge.

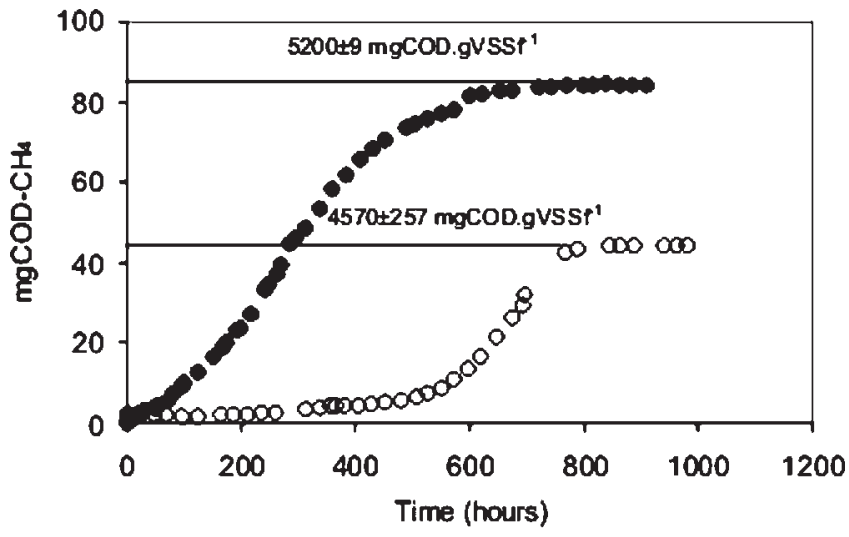

Figure 4. Cumulative methane production during the mineralization of the biomass-associated LCFA present in sludge from RI $(O)$ and from RII (O). The specific LCFA content of each sludge is indicated in the graph. $\mathrm{VSS}_{\mathrm{f}}$ are the VSS measured at the end of the assay.

plateau achieved in the cumulative methane production curves was considered an indirect measurement of the amount of accumulated LCFA (Pereira et al., 2002, 2004).

Specific LCFA contents of 4,570 \pm 257 and of 5,200 \pm $9 \mathrm{mg} \mathrm{COD} / \mathrm{g}$ VSS were found to be present in sludge 1 and 2, respectively. In both sludges, the mineralization process lasted approximately $800 \mathrm{~h}$. In sludge 1, a lag phase of about $500 \mathrm{~h}$ was observed to precede the initial methane production.

Both LCFA-loaded sludge were characterized in terms of SMA in the presence of acetate, propionate, butyrate, ethanol and $\mathrm{H}_{2} / \mathrm{CO}_{2}$. Figure 5 presents the methane production results.

As it can be observed in Figure 5, sludge 2 ("nonencapsulated") exhibited a considerable initial methane production rate from all the tested substrates with the single exception of butyrate. Also the blank control tests, where only the accumulated palmitic acid was present, exhibited a significant initial methane production rate. However, for sludge 1 (encapsulated) only methane production from ethanol and $\mathrm{H}_{2} / \mathrm{CO}_{2}$ was detected, after a lag phase of about $50 \mathrm{~h}$. As referred before, in this sludge, LCFA accumulated in intimate contact with the biomass, and thus, besides the potential inhibitory effect, it is reasonable to expect that the accumulation of LCFA onto this biomass can create a physical barrier and hinder the transfer of substrates and products (e.g., biogas release), inducing a delay on the initial methane production. Transport limitations phenomena may be responsible by the observed lag phases generally reported to be ascribed to mechanisms of cell wall damage or to cell adaptation to the toxic. This hypothesis is reinforced by the fact that $\mathrm{H}_{2}$, the smallest substrate tested, was the first to be transformed into methane, suggesting a faster transport of this molecule through the LCFA layer than the observed for the other substrates. This is in accordance with the absence of lag phases and slight inhibition of hydrogen consumption, reported in the assessment of hydrogenophilic activity in the presence of LCFA (Hanaki et al., 1981; Lalman and Bagley, 2000, 2001; Pereira et al., 2003). For the encapsulated sludge, 

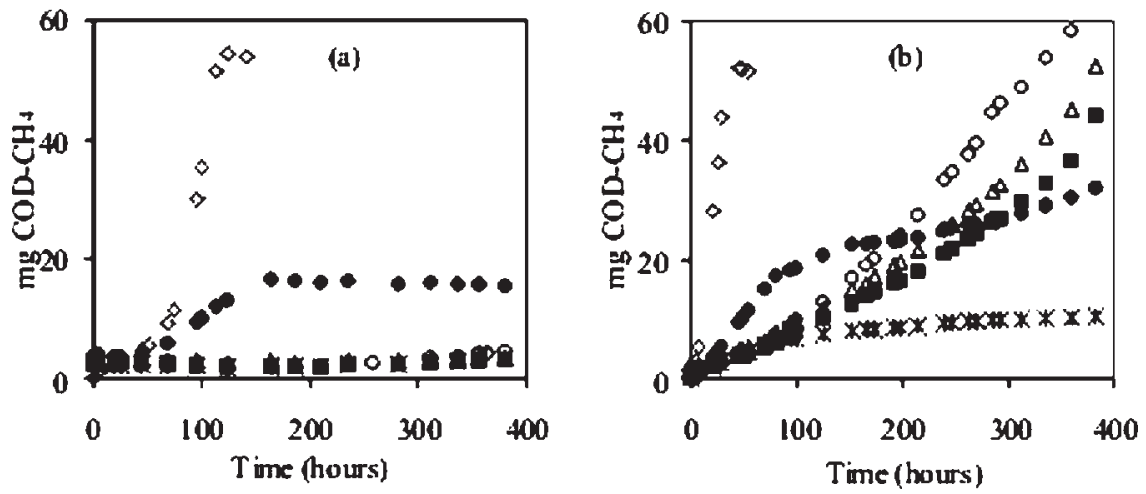

Figure 5. Cumulative methane production curves obtained for (a) sludge 1 and (b) sludge 2, during the methanogenic activity measurement with ( $\Delta$ ) acetate, $(\square)$ propionate, $(\times)$ butyrate, $(\bigcirc)$ ethanol and $(\diamond) \mathrm{H}_{2} / \mathrm{CO}_{2}$ as substrates, and $(\bigcirc)$ in the "blank" control (mineralization of the biomass-associated LCFA).

methane production from ethanol was also observed, likely because it dissolved the accumulated LCFA, overcoming, to some extent, diffusion limitations. In sludge 2, the accumulated LCFA was in a loosely association with the cells "nonencapsulated," and thus mass transfer limitations are not expected to occur in a similar extent as in sludge 1.

Notwithstanding the importance of transport limitations, a reversible metabolic inhibition should not be disregarded. In fact, in sludge 2 , the presence of butyrate severely inhibited methane production, and the presence of acetate and propionate induced a delay on the mineralization of the biomassassociated LCFA. Since, as described in the Materials and Methods, the SMA values are, by definition, obtained after discounting the background methane production obtained in the blank controls (mineralization of the biomass-associated LCFA), the delay caused by the presence of acetate and propionate will, thus, result in null activity values against those substrates. Table VI summarizes the SMA values exhibited by both sludge, before and after allowing the mineralization of the accumulated LCFA.

As shown in Table VI, after mineralization of the biomassassociated LCFA, both sludge exhibited activities significantly higher than before, except with propionate as substrate. The seed sludge used in this work exhibited already non-detectable activity in the presence of this substrate

Table VI. Specific methanogenic activities exhibited by sludge 1 and sludge 2, before and after mineralization of the biomass-associated LCFA (mean $\pm \mathrm{SD})$.

Specific methanogenic activity (mg COD- $\mathrm{CH}_{4} / \mathrm{g}$ VSS/day)

\begin{tabular}{lccccc}
\hline & \multicolumn{2}{c}{${\text { Sludge } 1^{\mathrm{a}}}_{\text {In the }}$} & & \multicolumn{2}{c}{ Sludge 2 } \\
\cline { 2 - 3 } \cline { 5 - 6 } presence of & Before & After & & Before & After \\
\hline Acetate & 0 & $533 \pm 95$ & & 0 & $454 \pm 5$ \\
Propionate & 0 & $16 \pm 5$ & & 0 & $41 \pm 3$ \\
Butyrate & 0 & $224 \pm 71$ & & 0 & $110 \pm 9$ \\
Ethanol & $24 \pm 6$ & $67 \pm 1$ & & $155 \pm 8$ & $138 \pm 11$ \\
$\mathrm{H}_{2} / \mathrm{CO}_{2}$ & $401 \pm 21$ & $2709 \pm 38$ & & $2351 \pm 33$ & $3224 \pm 182$ \\
\hline
\end{tabular}

${ }^{\text {a}}$ Pereira et al., 2004.
(Table I), and thus, no discussion can be addressed about the effect of LCFA-long term contact on this particular trophic group. Concerning the methanogenic activity in the presence of the other tested substrates, the reversibility of LCFA inhibitory/transport limitations effect is evident. From the obtained results, it is remarkable to observe that after depletion of the accumulated LCFA, both sludge exhibited activities of similar order of magnitude. It is therefore possible hypothesize that both sludge had also similar intrinsic activities before degrading the accumulated LCFA and that the different pattern on the methane production curves, before degrading the biomass-associated LCFA, resulted mostly from the different way/degree of LCFA association with the biomass. Since sludge 1 resulted from the continuous load with oleic acid, apparently more inhibitory than palmitic acid (Table I), the possibility of being submitted to higher toxic load, which may have induced a lower activity, could therefore be speculated. However, the transformation of oleic acid to palmitic acid was found to be a fast and nonlimiting step in oleic acid degradation, and thus, palmitic acid was, in fact, the main LCFA that contacted for a long term with both sludge. Hence, the hypothesis that they may have a similar state of intrinsic activity while LCFA-loaded, seems to be a feasible consideration.

Other aspect that should be pointed out is that, during the mineralization of the biomass-associated LCFA growth can occur, and thus, besides the elimination of LCFA reversible inhibitory/transport limitation effects, the enrichment of specific populations in the consortium during this mineralization process, may have been also promoted. During oleate/palmitate $\beta$-oxidation both butyrate and acetate should be formed, which may result in the enrichment of both aceticlastic methanogens and acetogenic butyratedegraders bacteria. The same can occur with hydrogenotrophic methanogens, an important group that acts syntrophically with hydrogen producing acetogenic bacteria during LCFA degradation. This may be related with the considerable increase on the activity in the presence of acetate, butyrate, and $\mathrm{H}_{2} / \mathrm{CO}_{2}$ exhibited by the sludge after depletion of the biomass-associated LCFA (Table VI), when compared to the previously exhibited by the seed sludge (Table I) On 
the opposite, being propionate a less probable intermediate of oleate/palmitate $\beta$-oxidation, an enhancement of sludge activity in these substrates may, therefore, not be promoted.

\section{CONCLUSIONS}

The results obtained in this work evidence the important role of transport limitations imposed by LCFA in the anaerobic digestion process. Besides the potential toxic effect, LCFA accumulation onto the sludge can create a physical barrier and hinder the transfer of substrates and products (e.g., biogas release), inducing a delay on the initial methane production. Although metabolic inhibition of LCFA may also occur, the important feature is that the metabolic or physical effect that is behind a temporary decrease in the methanogenic activity is a reversible phenomenon, which is eliminated after the mineralization of the biomass-associated LCFA.

We grateful acknowledge Fundação para a Ciência e Tecnologia (FCT) and Fundo Social Europeu (FSE) for the financial support given to Alcina Pereira through the grant PRAXIS XXI/BD/20326/99.

\section{References}

Alves MM, Mota Vieira JA, Álvares Pereira RM, Pereira MA, Novais JM, Mota M. 2001. Effects of lipids and oleic acid on biomass development in anaerobic fixed bed reactors. Part I: Biofilm growth and activity. Wat Res 35:255-263.

Angelidaki I, Ahring BK. 1992. Effects of free long-chain fatty acids on thermophilic anaerobic digestion. Appl Microbiol Biotechnol 37:808812.

APHA, AWWA, WPCF. 1989. Standard methods for the examination of water and wastewater, 17th edn. Washington, DC: American Public Health Association.

Beccari M, Majone M, Torrisi L. 1998. Two-reactor system with partial phase separation for anaerobic treatment of olive oil mill effluents. Wat Sci Tech 38:53-60.
Coates JD, Coughlan MF, Colleran E. 1996. Simple method for the measurement of the hydrogenotrophic methanogenic activity of anaerobic sludges. J Microbiol Methods 26:237-246.

Colleran E, Concannon F, Goldem T, Geoghegan F, Crumlish B, Killilea E, Henry M, Coates J. 1992. Use of methanogenic activity tests to characterize anaerobic sludges, screen for anaerobic biodegradability and determine toxicity thresholds against individual anaerobic trophic groups and species. Wat Sci Technol 25:31-40.

Dolfing J, Bloemen WGBM. 1985. Activity measurements as a tool to characterize the microbial composition of methanogenic environments. J Microbiol Methods 4:1-12.

Galbraith H, Miller TB. 1973. Physicochemical effects of long chain fatty acids on bacterial cells and theirs protoplasts. J Appl Bact 36:647-658.

Gujer W, Zehnder AJB. 1983. Conversion processes in anaerobic digestion. Wat Sci Technol 15:127-167.

Hanaki K, Matsuo T, Nagase M. 1981. Mechanisms of inhibition caused by long chain fatty acids in anaerobic digestion process. Biotechnol Bioeng 23:1591-1610

Hwu C-S. 1997. Enhancing anaerobic treatment of wastewaters containing oleic acid. Ph.D. Thesis, Wageningen Agricultural University, The Netherlands.

Lalman JA, Bagley DM. 2000. Anaerobic degradation and inhibitory effects of linoleic acid. Wat Res 34:4220-4228.

Lalman JA, Bagley DM. 2001. Anaerobic degradation and methanogenic inhibitory effects of oleic and stearic acids. Wat Res 35:2975-2983.

Pereira MA, Cavaleiro AJ, Mota M, Alves MM. 2003. Accumulation of LCFA onto anaerobic sludge under steady state and shock loading conditions: Effect on acetogenic and methanogenic activity. Wat Sci Technol 48:33-40

Pereira MA, Pires OC, Mota M, Alves MM. 2002. Anaerobic degradation of oleic acid by suspended and granular sludge: Identification of palmitic acid as a key intermediate. Wat Sci Technol 45:139-144.

Pereira MA, Sousa DZ, Mota M, Alves MM. 2004. Mineralization of LCFA associated to anaerobic sludge: Kinetics, enhancement of methanogenic activity and effect of VFA. Biotechnol Bioeng 88(4):502-511.

Rinzema A, Boone M, Van Knippenberg K, Lettinga G. 1994. Bactericidal effect of long chain fatty acids in anaerobic digestion. Wat Environ Res 66:40-49.

Roy F, Albagnac G, Samain E. 1985. Influence of calcium addition on growth of highly purified sintrophic cultures degrading long chain fatty acids. Appl and Environ Microbiol 49:702-705.

Salminen E, Einola J, Rintala J. 2001. Characterisation and anaerobic batch degradation of materials accumulating in anaerobic digesters treating poultry slaughterhouse waste. Env Technol 22(5):577-585.

Yang J, Speece RE. 1986. The effects of chloroform toxicity on methane fermentation. Wat Res 20:1273-1279. 